\title{
Concurrent use of amphetamine stimulants and antidepressants by undergraduate students
}

\author{
This article was published in the following Dove Press journal: \\ Patient Preference and Adherence \\ 22 January 2015 \\ Number of times this article has been viewed
}

\author{
Kim Vo' \\ Patricia J Neafsey ${ }^{2}$ \\ Carolyn A Lin ${ }^{3}$ \\ 'University of Connecticut Health \\ Center, Farmington, ${ }^{2}$ School of Nursing \\ and Center for Health Information \\ and Prevention, University of \\ Connecticut, Storrs, ${ }^{3}$ Department of \\ Communication Sciences and Center \\ for Health Information and Prevention, \\ University of Connecticut, Storrs, CT, \\ USA
}

Correspondence: Carolyn A Lin Department of Communication, 337 Mansfield Road, University of Connecticut, Storrs, CT 06269-1295, USA Email carolyn.lin@uconn.edu

\begin{abstract}
Undergraduate students were recruited to participate in an online survey to report their use of amphetamine stimulants and other drugs. Significant differences were found between students reporting $(n=79 ; 4.0 \%)$ and not reporting $(n=1,897 ; 96 \%)$ amphetaminestimulant use in the past month - in terms of race/ethnicity, class standing, residence, health symptoms, self-health report - in addition to alcohol, tobacco, pain-reliever, and antidepressant use. Health symptoms reported more often by stimulant users included depression, diarrhea, difficulty sleeping, fatigue, dizziness, difficulty concentrating, and nicotine craving. Health care providers of college students should query these patients about symptoms that could be related to depression and amphetamine use. In particular, they should provide education at the point of care around the risks of amphetamine use in general and the specific risks in those students who have symptoms of depression and/or are taking antidepressant medication. Prevention programs should also target the risks of concurrent use of amphetamines, antidepressants, and other drugs among college students.
\end{abstract}

Keywords: stimulant use, depression, college students, self-medication

\section{Introduction}

Misuse of amphetamine psychostimulants (eg, methylphenidate such as Ritalin ${ }^{\circledR}$, Concerta $^{\circledR}$ ), amphetamine/dextroamphetamine [Adderall ${ }^{\circledR}$ ], lisdexamfetamine dimesylate [Vyvanse ${ }^{\mathrm{TM}}$ ]) and other unsafe self-medication practices among college students are an important and serious threat to student health across the nation's college campuses. Prescriptive stimulants are federally mandated schedule II controlled substances (CIIs), due to their high potential for abuse that may lead to psychological and physical dependence. ${ }^{1}$ According to US Drug Enforcement Administration (DEA) regulations, physicians are authorized to prescribe up to a 90-day supply of a CII substance per visit without refills. ${ }^{2}$ Despite federal prescriptive-stimulant regulations, large-scale college student studies have documented the prevalence of undergraduates using non-prescribed stimulants as $2 \%$ to $8 \% 0^{3-5}$ in the past month and $3 \%$ to $16 \%$ in the past year. ${ }^{5-8}$ In a northeastern university, 34\% of respondents reported taking non-prescribed amphetamines. ${ }^{7}$ Another study conducted at a mid-western university indicated that self-reported past-year use of amphetamines significantly increased from $5 \%$ in 2003 to $9 \%$ in $2013 .^{8}$

Concurrent use of stimulants with antidepressants is a high-risk behavior and is medically contraindicated ${ }^{9}$ due to potential cytochrome P450 2D6 (CYP2D6) enzyme inhibition and a resulting increase in serotonin levels. Specifically, using stimulants to self-medicate depression is counterproductive, as stimulants can precipitate depressive symptoms and exacerbate existing depression. Likewise, amphetamine stimulants can cause a host of adverse symptoms such as cardiac dysrhythmias, anxiety, high 
blood pressure, difficulty sleeping, diarrhea, dizziness, and unsteadiness. ${ }^{9}$ Student misperceptions of nonmedical stimulant use as being "physically harmless"10-12 are cause for concern. As concurrent use of stimulants, alcohol, and/or other medications is common among college students, ${ }^{8,13}$ this suggests that students are mostly unaware of the adverse consequences of such mixed use. ${ }^{10,12}$ To further investigating the self-medication practices of undergraduate students, the study reported here focused on concurrent use of amphetamine stimulants and antidepressants, in addition to other drug-use and lifestyle factors.

\section{Methods}

Undergraduate students who were 18 years old or older from a large northeastern university were recruited as respondents in an online survey via an email during October of 2011. The university required students to link their university email address to their private email addresses, thus ensuring receipt of listserv emails by all undergraduates. The email briefly described the survey objectives and provided the web link to the survey, which was available for a 2 -week period. This message also instructed students to copy and paste the survey web address into a browser to ensure anonymity. The email message was sent to 17,450 students. The response rate was $13.1 \% ; 2,281$ surveys were completed.

\section{Survey instrument}

An ActualMeds ${ }^{\mathrm{TM}}$ online survey (designed for touch screen use) that was previously validated by the principal investigator's research team for assessing self-medication behavior in older adults was modified and then adopted for this research study. ${ }^{14,15}$ The medication database that is linked to the ActualMeds online survey included such agents as marijuana, methamphetamine, energy drinks (eg, Monster Energy ${ }^{\circledR}$, Red Bull $^{\circledR}, 5$-Hour Energy ${ }^{\mathrm{TM}}$, etc), caffeine (ie, pills and gum such as Jolt ${ }^{\circledR}$, Penguin ${ }^{\circledR}$, Blitz ${ }^{\circledR}$, etc), chewing tobacco, ecstasy, protein supplements (eg, whey protein, creatine, Opti-Men ${ }^{\mathrm{TM}}$, Muscle Milk ${ }^{\circledR}$, etc), and food (eg, coffee, tea, espresso, soda, milk, carbohydrates, bread, and hot sauce). Colloquial terms for each agent were also used in the survey (eg, molly, weed, juice, coke, and roofies). The research team fact-checked the accuracy of the medication data linked to the online survey and ascertained the survey's usability by testing it four different times before administering the survey.

The survey items included four categories of questions: (1) demographics, (2) lifestyle, (3) health conditions and symptoms, and (4) medication use. Demographic questions inquired about characteristics such as gender, class standing, race/ethnicity, student-group affiliations (eg, sports, groups, sororities, and fraternities), residence (eg, campus or offcampus housing), and most frequented meal locations.

Questions that measure the general lifestyle profile included, for instance, amount of exercise in the last month, hours of sleep per night, smoking status (cigarettes and chewing tobacco), nicotine craving, energy drink/supplement consumption, and the primary medical information source. Respondents were also asked if they had consumed wine, beer, or liquor in the past month. If they selected "yes" to this question, they were prompted to provide a response to questions on the following: (1) the number of drinks they would have on a typical day; (2) how many days a week they drank; (3) what they usually took, if anything, prior to consuming alcohol; (4) what they mixed, if anything, with the alcohol consumed; and (5) what they took, if anything, to treat a hangover. To ensure consistency in drink-size measurement, an image of a standard drink reference was displayed.

Survey questions that assessed respondents' health contained such items as all medical conditions in the past year (via a drop-down menu), the presence of any health symptoms in the past month (via a drop-down menu), and a self-rating of one's own health in the past month (via the scale "poor, fair, average, good, or very good"). Medication-use questions (dichotomously coded) asked respondents which medication they used, if any, to care for common conditions or illnesses such as eye issues, diabetes, low thyroid, depression, pain, anxiety, indigestion, allergies, colds, or sinus problems. Other medication questions queried respondents which medication or supplement they took, if any, to help them sleep, stay awake, improve sexual performance, lose weight, gain muscle, or improve athletic performance. Additional medication questions probed respondents about whether they took any other prescribed or over-the-counter (OTC) medications or nutrition supplements (ie, vitamins, minerals, or herbs).

For the medication-use questions, if respondents answered an affirmative to any of them, they were directed to a database that provided an A-Z drop-down list to identify the agent(s) that they took (including prescribed and OTC medications, nutrition supplements, herbals, and alcohol and tobacco products). Respondents were also given the option to type in the agent(s) they used for each question, if the generic or brand name of the agent was not available in the database. For example, a respondent could report several different pain relievers in response to the question "What did you use for pain in the past month?" For each agent chosen or entered, the respondents were also directed to: (1) answer how many 
days a week they had taken it over the past month and (2) report how much, when, and how many times they took the agent by clicking on a 24-hour clock face. Following that, respondents were redirected to answer the other remaining questions.

\section{Data analysis}

Of the 2,281 online surveys collected, 280 (12\%) incomplete and $25(1.1 \%)$ invalid surveys were removed from the data analysis. Incomplete surveys were those that had three or more missing demographic answers. An example of an invalid survey response contained a positive answer to taking an unrealistic list of the following medications and daily dosages for pain: one Omnaris ${ }^{\circledR}$, seven Zyrtec $^{\circledR}$, twelve marijuana, six ibuprofen, and six Vyvanse. Gender, race/ethnicity, class standing, current residence, group affiliation, selfhealth reports, number of hours of sleep per night, exercise, health conditions, health symptoms, and medication use were reported as frequencies.

Self-medication frequency associated with the use of each medication was obtained via matching the self-reported medication name/brand with the medication identification numbers extracted from the medication database of the ActualMeds survey. Medication counts were computed based on the number of respondents who answered positively to each single-agent category. To calculate medication-category percentages, each category was divided by the total different number of respondents who provided at least one rationale for the use of an agent. The categorical variables were calculated as frequencies and percentages. Chi-square or Fisher's exact tests, using SAS/STAT ${ }^{\circledR}$ software (v 9.2), ${ }^{16}$ were applied to compare respondents: (1) who reported taking stimulants to those who did not and (2) who reported taking prescription medications for depression concurrently with stimulants to

Table I Demographic characteristics of stimulant users and nonusers

\begin{tabular}{|c|c|c|c|c|c|c|}
\hline \multirow[t]{2}{*}{ Characteristic } & \multirow[t]{2}{*}{ Users, n (\%) } & \multirow[t]{2}{*}{ Nonusers, n (\%) } & \multirow[t]{2}{*}{$\chi^{2}$ (P-value) } & \multicolumn{2}{|c|}{ Use $\mathbf{R x}$ for depression } & \multirow[t]{2}{*}{$\chi^{2}$ (P-value) } \\
\hline & & & & Users, n (\%) & Nonusers, n (\%) & \\
\hline Gender & & & NS & & & NS \\
\hline Female & $54(68)$ & I,338 (7I) & & $12(80)$ & $78(92)$ & \\
\hline Male & $25(32)$ & $559(29)$ & & $3(20)$ & $7(8.2)$ & \\
\hline Race/Ethnicity & & & $12.5(0.029)$ & & & \\
\hline White & $70(89)$ & I,42I (75) & & $12(80)$ & $77(91)$ & $N^{a}$ \\
\hline Asian & $3(3.8)$ & $185(9.8)$ & & I (1.6) & $2(2.4)$ & \\
\hline Black/African American & $0(0)$ & $132(7)$ & & $0(0)$ & $0(0)$ & \\
\hline Hispanic & $2(2.5)$ & 74 (3.9) & & I (6.7) & $3(3.5)$ & \\
\hline More than one race & I (I.2) & $49(2.6)$ & & $0(0)$ & $2(2.4)$ & \\
\hline Other & $3(3.8)$ & $36(1.9)$ & & $0(0)$ & $0(0)$ & \\
\hline Class standing & & & I I. $22(0.0 \mid \mathrm{I})$ & & & $N S^{a}$ \\
\hline Freshman & II (I4) & $528(28)$ & & $4(2.7)$ & $15(18)$ & \\
\hline Sophomore & $17(22)$ & $486(26)$ & & $2(13)$ & $22(26)$ & \\
\hline Junior & $28(35)$ & $448(24)$ & & $3(20)$ & $24(28)$ & \\
\hline Senior & $22(28)$ & $433(23)$ & & $6(40)$ & $24(28)$ & \\
\hline Living/residency & & & $39.78(<0.001)$ & & & $N S^{a}$ \\
\hline Dorm room & $39(49)$ & $1,366(72)$ & & $8(53)$ & $56(66)$ & \\
\hline Off-campus apartment & $27(34)$ & $371(20)$ & & $5(33)$ & $23(27)$ & \\
\hline At home & $3(3.8)$ & I $14(6)$ & & $2(13)$ & $5(5.9)$ & \\
\hline Sorority/fraternity & $4(5)$ & $14(0.7)$ & & $0(0)$ & $0(0)$ & \\
\hline Other & $5(6.3)$ & $30(1.6)$ & & $0(0)$ & I (I.2) & \\
\hline No answer & I (I.2) & $2(0.1)$ & & $0(0)$ & $0(0)$ & \\
\hline Group affiliation & & & NS & & & $N S^{a}$ \\
\hline None & $24(30)$ & $514(27)$ & & $8(53)$ & $20(24)$ & $0.028^{b}$ \\
\hline Sorority/fraternity & $16(20)$ & $252(13)$ & & I (6.7) & $13(15)$ & \\
\hline Club sports team & $8(10)$ & $200(10)$ & & I (6.7) & $2(2.4)$ & \\
\hline Intramural sports team & $17(22)$ & $424(22)$ & & I (6.7) & $16(19)$ & \\
\hline Preprofessional group & $21(27)$ & $499(26)$ & & $2(13)$ & $23(27)$ & \\
\hline Cultural-center group & $6(7.6)$ & $256(13)$ & & $2(13)$ & $7(8.2)$ & \\
\hline Division I sports team & $3(3.8)$ & $60(3.2)$ & & I (6.7) & $6(7.1)$ & \\
\hline Music - dance group & $4(5)$ & $187(9.9)$ & & I (6.7) & $5(5.9)$ & \\
\hline Student government & $0(0)$ & $119(6.3)$ & & $0(0)$ & $9(11)$ & \\
\hline
\end{tabular}

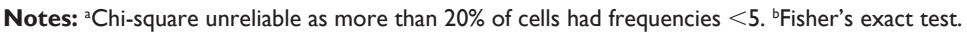
Abbreviations: NS, nonsignificant; Rx, prescription(s). 
those who did not. The level of significance was set a priori at $P<0.05$.

Hierarchical binary logistic regressions using the logit function (inverse of the cumulative logistic distribution function) were conducted to evaluate the relationship between sets of predictor variables and stimulant use among respondents who reported taking a prescription medication to treat depression.

\section{Results}

The 1,976 complete and reliable surveys $(n=1,392 ; 70 \%$ female) represented approximately $11 \%$ of the undergraduate population at the university. ${ }^{17}$ Participant class standing was as follows: freshmen $(\mathrm{n}=539 ; 27 \%)$, sophomores $(\mathrm{n}=503$; $26 \%)$, juniors $(n=476 ; 24 \%)$, and seniors $(n=455 ; 23 \%)$. Overall, 79 (4.0\%) survey respondents reported using a stimulant in the past month and $68 \%$ of them were female. The university's institutional review board did not permit the investigation of nonmedical or medical use of stimulants among survey respondents; therefore, the use of the word "stimulant" can refer to either prescribed or non-prescribed stimulants in this paper. The stimulants respondents reported using include Adderall, Vyvanse, Ritalin/methylphenidate, Concerta, and dextroamphetamine.

The reported reasons for stimulant use included the following: (1) to improve mental performance $(n=61 ; 77 \%),(2)$ to stay awake $(n=27 ; 34 \%),(3)$ to mix with alcohol $(n=6$; $7.6 \%)$, (4) to control anxiety/depression ( $n=5 ; 6.3 \%),(5)$ to prepare for drinking alcohol $(\mathrm{n}=2 ; 2.5 \%)$, (6) to gain pain relief ( $\mathrm{n}=2 ; 2.5 \%)$, and/or $(7)$ to lose weight $(\mathrm{n}=1 ; 1.3 \%)$. Six students $(7.6 \%)$ did not report a reason for use other than "prescribed medication". These results correspond to the rationales of nonmedical use of stimulants found in past studies. ${ }^{18-21}$

Table 1 presents the comparisons between self-reported stimulant users and non-stimulant users across a set of key variables. Consistent with the current literature that suggests stimulant use is the highest among the Caucasian population, ${ }^{8,13,22-24}$ race/ethnicity was significant in this study $(P<0.05)$. While $89 \%$ of the stimulant users were white, $4 \%$ were Asian, and none were black. By comparison, 75\% of nonusers were white, $10 \%$ were Asian, and 7\% were black. The literature suggests that stimulant use is either similar between males and females or higher in the male population..$^{8,13,20-22}$ No difference was found between genders in relation to stimulant use in this survey. Likewise, an individual's group affiliation, exercise level, health conditions in the past year, sleep, and sources of medication information were not significantly different between stimulant users and nonusers in this study.

Class standing was statistically significant between respondents reporting and not reporting stimulant use $(P<0.01)$. Of respondents indicating stimulant use, 11\% were freshmen and $35 \%$ were juniors. By contrast, $28 \%$ and $24 \%$ freshmen and juniors did not report stimulant use, respectively. Current residence was also significantly differentiated $(P<0.001)$. Specifically, 39\% of respondents who reported stimulant use lived in an off-campus apartment or fraternity/ sorority housing, compared with the $21 \%$ of respondents who did not report stimulant use.

Alcohol use was significantly different between stimulant users and nonusers $(P<0.001)$. Among stimulant users, 91\% replied "yes" to the question asking whether they drank wine, beer, or liquor, compared with $60 \%$ of nonusers who stated the same (Table 2). These findings confirmed two prior national survey results regarding alcohol and amphetamine-stimulant use among full-time college students. ${ }^{25,26}$ Nearly half (46\%) of stimulant users who reported drinking alcohol consumed alcohol on 3 or more days per week - and/or had three or more drinks in one sitting at least once per week - compared with $36 \%$ of non-stimulant users who also reported drinking alcohol. Of respondents reporting stimulant use, $11 \%$ indicated using stimulants either to "prepare for drinking" or "to mix with alcohol". Moreover, 52\% of stimulant users probably had steady-state levels of amphetamine stimulants in their bloodstream, since they reported using them "daily", "three days or more per week", or "when I remembered to take it". Eighty-nine percent of the students who took stimulants this frequently also reported drinking alcohol, with 53\% of them drinking alcohol three or more times per week and/or having three or more drinks in one sitting.

Smoking in the past month was reported by $22 \%$ of the students surveyed. This finding is similar to that of the National College Health Assessment - which documented an overall $24 \%$ smoking rate in the prior month - based on a 2009 survey of 30,093 students from 39 colleges by the American College Health Association. ${ }^{27}$ In the current survey, significantly more (42\%) stimulant users reported smoking cigarettes and/or smokeless (chewing) tobacco than nonusers (21\%) of stimulants $(P<0.001)$. These findings supported prior results of an American College Health AssociationNational College Health Assessment survey of 10,220 fulltime undergraduates, wherein twice as many stimulant users than nonusers reported smoking cigarettes. ${ }^{26}$ In the current survey, chewing tobacco was reported by $7.6 \%$ of stimulant users but only $1.2 \%$ of nonusers of stimulants $(P<0.001)$. 
Table 2 Lifestyle characteristics of stimulant users and nonusers

\begin{tabular}{|c|c|c|c|c|c|c|}
\hline \multirow[t]{2}{*}{ Characteristic } & \multirow[t]{2}{*}{ Users, n (\%) } & \multirow[t]{2}{*}{ Nonusers, n (\%) } & \multirow[t]{2}{*}{$\chi^{2}$ (P-value) } & \multicolumn{2}{|c|}{ Use Rx for depression } & \multirow[t]{2}{*}{$\chi^{2}$ (P-value) } \\
\hline & & & & Users, n (\%) & Nonusers, n (\%) & \\
\hline Sleep per night, hours & & & NS & & & $N S^{b}$ \\
\hline Under 5 & $3(3.8)$ & $66(3.5)$ & & $2(13)$ & $\mathrm{I}(\mathrm{I} .2)$ & \\
\hline $5-6$ & $33(42)$ & 748 (39) & & $6(40)$ & $34(40)$ & \\
\hline $7-8$ & $39(49)$ & $990(52)$ & & $4(27)$ & $39(46)$ & \\
\hline Over 8 & $4(5.1)$ & $92(4.8)$ & & $3(20)$ & II (I3) & \\
\hline Exercise & & & NS & & & NS ${ }^{b}$ \\
\hline A few times a month & $20(25)$ & $466(25)$ & & $5(33)$ & $28(33)$ & \\
\hline A few times a week & $35(44)$ & 721 (38) & & $4(27)$ & $23(27)$ & \\
\hline Daily & $7(8.9)$ & $268(14)$ & & $0(0)$ & $16(19)$ & \\
\hline Once a week & $4(5.1)$ & $23 \mid(\mid 2)$ & & I (6.7) & $7(8.2)$ & \\
\hline Not at all & $13(16)$ & $2 I I(I I)$ & & $5(33)$ & $11(13)$ & \\
\hline Alcohol use & & & $23.43(<0.001)$ & & & NS ${ }^{b}$ \\
\hline Yes & $72(91)$ & $\mathrm{I}, \mathrm{I} 43(60)$ & & II (73) & $59(69)$ & \\
\hline No & $2(2.5)$ & $273(14)$ & & $0(0)$ & $10(12)$ & \\
\hline I never drink & $5(6.3)$ & $346(18)$ & & $4(27)$ & $14(16)$ & \\
\hline No answer & $0(0)$ & $135(7.1)^{\mathrm{a}}$ & & $0(0)$ & $2(2.4)$ & \\
\hline \multicolumn{7}{|l|}{ Tobacco use } \\
\hline Cigarettes or chewing tobacco & $33(42)$ & $392(21)$ & $<0.00 \mathrm{I}^{\mathrm{c}}$ & $0(0)$ & $13(15)$ & $N S^{c}$ \\
\hline Chewing tobacco & $6(7.6)$ & $23(1.2)$ & $<0.00 \mathrm{I}^{\mathrm{c}}$ & $0(0)$ & $0(0)$ & $N S^{c}$ \\
\hline None & $46(58)$ & I,505 (79) & & $15(100)$ & $72(85)$ & \\
\hline Energy drinks/supplements & $4(5.1)$ & $54(2.8)$ & $N S^{c}$ & $0(0)$ & $\mathrm{I}(\mathrm{I} .2)$ & $N S^{c}$ \\
\hline Sources of medical information & & & NS & & & $N S^{b}$ \\
\hline Family & $45(57)$ & $|, 22|(63)$ & & $3(20)$ & $44(52)$ & \\
\hline Labels & $20(25)$ & $438(23)$ & & $6(40)$ & $22(26)$ & \\
\hline Friends & $12(15)$ & $277(15)$ & & $3(20)$ & $3(3.5)$ & \\
\hline Primary care provider & $7(8.9)$ & $262(14)$ & & $7(47)$ & 31 (37) & \\
\hline Magazines & $4(5.1)$ & $40(2.1)$ & & $0(0)$ & $\mathrm{I}(\mathrm{I} .2)$ & \\
\hline Coach & $0(0)$ & $17(0.9)$ & & $0(0)$ & $0(0)$ & \\
\hline
\end{tabular}

Notes: a Class standings were: $20 \%$ freshman, $17 \%$ sophomore, $37 \%$ junior, $27 \%$ senior. ${ }^{\text {b } C h i-s q u a r e ~ u n r e l i a b l e ~ a s ~ m o r e ~ t h a n ~} 20 \%$ of cells had frequencies $<5$. ${ }^{\mathrm{C} F i s h e r}$ 's exact test.

Abbreviations: NS, nonsignificant; Rx, prescription(s).

Furthermore, nicotine craving was a symptom for $32 \%$ of stimulant users, compared with only $3.3 \%$ of nonusers.

There was no significant difference in energy-drink/ caffeine-supplement use between those who used and did not use a stimulant. While energy drinks or caffeine supplements were reported by $2.9 \%$ of respondents, only less than $1 \%$ of respondents indicated use of caffeine supplements or energy drinks - before drinking alcohol or mixed with alcohol.

A significant difference was found in the self-rated health report between stimulant users and nonusers $(P<0.01)$. In particular, $24 \%$ of stimulant users rated themselves as having fair or poor health in the past month, compared with only $12 \%$ of nonusers who stated the same. Health symptoms over the past month identified by respondents who used stimulants were also significantly different from those who did not use stimulants $(P<0.001)$. Specifically, having difficulty concentrating was reported for $58 \%$ of stimulant users, compared with $34 \%$ of nonusers. The ratios of other health symptoms reported by stimulant users versus nonusers were: (1) fatigue: $66 \%$ versus $45 \%$, (2) difficulty sleeping: $66 \%$ versus $38 \%$, (3) depression: $33 \%$ versus $13 \%$, (4) diarrhea: $39 \%$ versus $22 \%$, (5) memory change: $11 \%$ versus $3.8 \%$, (6) dizziness: $33 \%$ versus $15 \%$, and (7) unsteadiness: $14 \%$ versus $6 \%$, respectively. Based on these findings, it appears that stimulant users experienced more negative health symptoms than nonusers.

Pain-reliever (prescription and OTC) use in the past month was reported by $65 \%$ of those who used stimulants and $52 \%$ of those who did not $(P<0.05)$. The National Survey on Drug Use and Health (NSDUH) survey found $45 \%$ of those taking Adderall for nonmedical reasons in the past year also took prescription pain relievers, compared with the $8.7 \%$ of those who did not use Adderall. ${ }^{25}$ In the current study $7.6 \%$ of stimulant users (who use any amphetamine stimulant including Adderall for any reason) and $2.8 \%$ of the nonusers reported taking a prescription pain reliever in the past month $(P<0.001)$. 
Concurrent prescriptions for depression (Table 3) were reported by $19 \%$ of those who used stimulants, compared with $4.1 \%$ of non-stimulant users $(P<0.001)$. Of those stimulant users indicating depression as a symptom, more than a third (38\%) took a selective serotonin reuptake inhibitor (SSRI) or serotonin-norepinephrine reuptake inhibitor (SNRI) to manage their symptoms (Table 3). Looking at this in a different way, of those students $(n=100)$ who used a prescription for treating depression, 15\% had also taken a stimulant in the past month, compared with $3.3 \%(n=64)$ of students not reporting the use of prescription depression medication. Of the 15 students reporting taking stimulants and prescription medication for treating depression concurrently, $80 \%$ took stimulants three or more times per week and $73 \%$ reported taking stimulants daily.

Chi-square analyses found no significant differences, when comparing students who concurrently took medication for depression and stimulants with those who did not take

Table 3 Health conditions and symptoms of stimulant users and nonusers

\begin{tabular}{|c|c|c|c|c|c|c|}
\hline \multirow[t]{2}{*}{ Characteristic } & \multirow[t]{2}{*}{ Users, n (\%) } & \multirow[t]{2}{*}{ Nonusers, n (\%) } & \multirow[t]{2}{*}{$\chi^{2}$ (P-value) } & \multicolumn{2}{|c|}{ Use Rx for depression } & \multirow[t]{2}{*}{$\chi^{2}(P$-value $)$} \\
\hline & & & & Users, n (\%) & Nonusers, n (\%) & \\
\hline Health self-report & & & $12.79(0.005)$ & & & $N S^{a}$ \\
\hline Good/very good & $38(48)$ & $1,213(64)$ & & $5(33)$ & $35(4 I)$ & \\
\hline Average & $22(28)$ & $459(24)$ & & $5(33)$ & $33(39)$ & \\
\hline Fair & $15(19)$ & $174(9.2)$ & & $3(20)$ & $10(12)$ & \\
\hline Poor & $4(5.1)$ & $49(2.6)$ & & $2(13)$ & $7(8.2)$ & \\
\hline No answer & $0(0)$ & $2(0.1)$ & & $0(0)$ & $0(0)$ & \\
\hline Health conditions in the last year ${ }^{c}$ & & & NS & & & $\mathrm{NS}^{\mathrm{a}}$ \\
\hline Anxiety & $40(5 I)$ & $436(23)$ & & $14(93)$ & $69(81)$ & \\
\hline Depression ${ }^{d}$ & $24(32)$ & $239(13)$ & & $13(87)$ & $63(74)$ & \\
\hline Asthma & $10(13)$ & $236(12)$ & & $0(0)$ & $9(I I)$ & \\
\hline Irregular heartbeat & $4(5.1)$ & $68(3.6)$ & & $2(13)$ & $3(3.5)$ & \\
\hline High blood pressure & $2(2.5)$ & $42(2.2)$ & & $0(0)$ & $0(0)$ & \\
\hline High cholesterol & $\mathrm{I}(\mathrm{I} .3)$ & $51(2.7)$ & & $0(0)$ & $0(0)$ & \\
\hline Health symptoms in the past month & & & $300.3(<0.001)$ & & & $\mathrm{NS}^{\mathrm{a}}$ \\
\hline Headache & $58(73)$ & $1,216(64)$ & & $14(93)$ & $64(75)$ & \\
\hline Difficulty sleeping & $52(66)$ & $717(38)$ & & $13(87)$ & $44(52)$ & $0.012^{b}$ \\
\hline Fatigue & $52(66)$ & $856(45)$ & & II (73) & $55(65)$ & \\
\hline Difficulty concentrating & $46(58)$ & $647(34)$ & & $11(73)$ & $45(53)$ & \\
\hline Cough & $41(52)$ & $793(42)$ & & $6(40)$ & $32(38)$ & \\
\hline Cold & $38(48)$ & $1,078(57)$ & & $6(40)$ & $42(49)$ & \\
\hline Pain & $36(46)$ & $703(37)$ & & $9(60)$ & $37(44)$ & \\
\hline Diarrhea & $31(39)$ & $422(22)$ & & $9(60)$ & $20(24)$ & \\
\hline Depression & $26(33)^{d}$ & $253(13)$ & & $9(60)$ & $50(59)$ & \\
\hline Dizziness & $26(33)$ & $290(15)$ & & $6(40)$ & $18(21)$ & \\
\hline Nicotine craving & $25(32)$ & $62(3.3)$ & & $6(40)$ & $4(4.7)$ & $<0.00 \mathrm{I}^{\mathrm{b}}$ \\
\hline Weight gain & $17(22)$ & $306(16)$ & & $4(27)$ & $18(21)$ & \\
\hline Weight loss & II (14) & $210(\mathrm{II})$ & & $2(13)$ & $12(14)$ & \\
\hline Unsteadiness & II (14) & $107(5.6)$ & & $2(13)$ & $5(5.9)$ & \\
\hline Constipation & $10(13)$ & $222(12)$ & & $3(20)$ & $15(18)$ & \\
\hline Skin change & $10(13)$ & $130(6.8)$ & & $2(13)$ & $7(8.2)$ & \\
\hline Memory change & $9(11)$ & $72(3.8)$ & & $2(13)$ & $5(5.9)$ & \\
\hline Vision changes & $7(8.9)$ & $90(4.7)$ & & I (6.7) & $6(7.1)$ & \\
\hline Bladder problems & $7(8.9)$ & $103(5.4)$ & & $2(13)$ & $6(7.1)$ & \\
\hline Falls or near fall & $4(5.1)$ & $73(3.8)$ & & $2(14)$ & $4(4.7)$ & \\
\hline Taste/smell change & $3(3.8)$ & $30(1.6)$ & & $0(0)$ & $0(0)$ & \\
\hline Prescription/OTC pain-reliever use & $51(65)$ & $983(52)$ & $0.026^{\mathrm{b}}$ & $12(80)$ & $4 \mid(48)$ & $0.027^{b}$ \\
\hline Prescription pain-reliever use & $6(7.6)$ & $54(2.8)$ & $<0.00 \mathrm{I}^{\mathrm{b}}$ & I (6.7) & $5(5.9)$ & $N S^{b}$ \\
\hline Prescription for depression & $15(19)^{e}$ & $77(4.1)$ & $<0.00 \mathrm{I}^{\mathrm{b}}$ & $15(100)^{\mathrm{e}}$ & $85(100)$ & \\
\hline
\end{tabular}

Notes: ${ }^{a}$ Chi-square unreliable as more than $20 \%$ of cells had frequencies $<5$. ${ }^{b}$ Fisher's exact test. 'Other conditions with frequencies $<2 \%$ were: arthritis, blood clots in the legs, cancer, diabetes, kidney disease, low thyroid, ulcer. ${ }^{\circ}$ Concurrent medications used for depression were reported by eleven (48\%) users reporting symptoms of depression; of these, two were nonprescription. eMedications prescribed for depression reported were: SSRIs (9), SSRI/SNRI (I), Wellbutrin (bupropion; 2), lithium (I), Mirapex ${ }^{\circledR}$ (pramipexole; I), Trilepta $^{\circledR}$ (oxcarbazepine; I).

Abbreviations: NS, nonsignificant; OTC, over the counter; Rx, prescription(s); SNRI, serotonin-norepinephrine reuptake inhibitor; SSRI, selective serotonin reuptake inhibitor. 
stimulants - with respect to the following demographic and lifestyle variables - race/ethnicity, class standing, living/ residency, number of hours of sleep per night, exercise, alcohol use, health self-report, health conditions in the past year, or symptoms in the past month. However, students taking both stimulants and prescription medication for depression reported a greater frequency - for no group affiliation $(P<0.05)$, difficulty sleeping $(P<0.05)$, nicotine craving $(P<0.001)$, and pain-reliever use $(P<0.05)-$ than students undergoing treatment for depression without reporting stimulant use.

Hierarchical binary logistic regressions using the logit function (inverse of the cumulative logistic distribution function) evaluated the relationship between sets of predictor variables and stimulant use among respondents who reported taking a prescription medication to treat depression. The predictor variables, chosen based on the results of two-tailed Fisher's exact tests (Tables 1 and 3), were: no group affiliation, difficulty sleeping, nicotine craving, and prescription/ OTC pain-reliever use. Bivariate correlations (zero-order Pearson's correlations) among the independent variables and dependent variable (user status) were computed to identify interactions. The Pearson correlation of nicotine craving with difficulty sleeping was $0.222(P=0.026)$. Therefore, this interaction of nicotine craving $\times$ difficulty sleeping was also assessed in the regressions.

Results from the initial binary logistic regression (additive model) are shown in Table 4 (goodness-of-fit tests for this model are shown in Table 5). Predictor values with $P$-values less than 0.1 were retained (ie, prescription/OTC pain-reliever use was omitted) in subsequent regressions. Backward stepwise binary logistic regression was conducted using the remaining significant predictor variables: no group affiliation, difficulty sleeping, and nicotine craving. Since bivariate correlations found a significant correlation of difficulty sleeping with nicotine craving, the interaction variable “difficulty sleeping $\times$ nicotine craving" was also assessed.
Two additional binary logistic regressions were performed by entering the main effects before interaction effects (ie, no group affiliation entered before difficulty sleeping $\times$ nicotine craving, followed by [1] nicotine craving [lowest $P$-value in the additive model] and [2] either difficulty sleeping or no group affiliation).

Difficulty sleeping did not improve the model $P$-value, adjusted R-squared, or goodness-of-fit statistics. Therefore, the final models tested no group affiliation, difficulty sleeping $\times$ nicotine craving, and nicotine craving. Removing the interaction term and retaining nicotine craving and no group affiliation resulted in lower chi-squares and $P$-values, indicating improved goodness-of-fit tests and a good model fit (Tables 6 and 7).

\section{Discussion}

The negative health consequences on the central nervous system associated with concurrent use of amphetamines with alcohol and other drugs have been well documented in the medical literature. As aforementioned, college students often mix prescription drugs - such as amphetamine stimulants and antidepressants with alcohol, other drugs, OTC medicines, and energy drinks - without being aware of the potentially dangerous interaction effects between these substances. ${ }^{8,28,29}$ Specifically, alcohol increases the release of methylphenidate from extended-release formulations of stimulants, which further increases the risk of anxiety, tachycardia, and high blood pressure. ${ }^{9}$ Concurrent use of stimulants (either amphetamines or caffeine) and alcohol can increase wakefulness and mask the depressant effects of alcohol on the central nervous system, until much larger amounts of alcohol have been consumed. ${ }^{30}$

Furthermore, stimulants can precipitate depressive symptoms. Thus, self-medicating depression with stimulants is counterproductive, as stimulants can exacerbate existing depression. ${ }^{9}$ Although methylphenidate and SSRIs have been prescribed to treat adolescents with

Table 4 Binary logistic regression model (additive) predicting stimulant use among those taking prescription medication for depression

\begin{tabular}{|c|c|c|c|c|c|c|c|}
\hline \multirow[t]{2}{*}{ Predictor } & \multirow[t]{2}{*}{ Coefficient } & \multirow[t]{2}{*}{ SE coefficient } & \multirow[t]{2}{*}{$Z$} & \multirow[t]{2}{*}{$P$-value } & \multirow[t]{2}{*}{ Odds ratio } & \multicolumn{2}{|l|}{$95 \% \mathrm{Cl}$} \\
\hline & & & & & & Lower & Upper \\
\hline Constant & -4.37379 & 1.03028 & -4.25 & 0.000 & & & \\
\hline No group affiliation & 1.36867 & 0.704357 & 1.94 & 0.052 & 3.93 & 0.99 & 15.63 \\
\hline Difficulty sleeping & 1.69038 & 0.880265 & 1.92 & 0.055 & 5.42 & 0.97 & 30.44 \\
\hline Nicotine craving & 2.14449 & 0.798576 & 2.69 & 0.007 & 8.54 & 1.78 & 40.84 \\
\hline Rx/OTC pain-reliever use & 0.806254 & 0.762883 & 1.06 & 0.291 & 2.24 & 0.50 & 9.99 \\
\hline
\end{tabular}

Notes: Log-likelihood -30.705 . Test that all slopes are zero: $G=22.804, d f=4, P$-value $=0.000$.

Abbreviations: $\mathrm{Cl}$, confidence interval; $d f$, degrees of freedom; OTC, over the counter; Rx, prescription; SE, standard error. 
Table 5 Goodness-of-fit tests

\begin{tabular}{llll}
\hline Method & Chi-square & df & P-value \\
\hline Pearson & 8.94813 & 7 & 0.256 \\
Deviance & 9.82565 & 7 & 0.199 \\
Hosmer-Lemeshow & 3.74996 & 4 & 0.441 \\
\hline
\end{tabular}

Abbreviation: $d f$, degrees of freedom.

attention deficit hyperactivity disorder (ADHD) and comorbid depression exhibiting symptoms of apathy and hypersomnia, ${ }^{31,32}$ concurrent use of stimulants with antidepressants without close medical monitoring could result in rare but serious adverse reactions for the following reasons. First, amphetamines are metabolized by the CYP2D6 enzyme in the liver. Genetic polymorphisms of CYP2D6 are common; poor metabolizers of CYP2D6 have higher blood levels of substrates metabolized by the enzyme. ${ }^{33}$ Commonly prescribed antidepressants such as SSRIs can inhibit CYP2D6, which can in turn increase serum concentrations and side effects of amphetamines. ${ }^{934}$ Second, amphetamines can increase serotonin release and inhibit reuptake; concurrent use of amphetamines with SSRIs can lead to dangerously high extracellular serotonin levels (serotonin syndrome) ${ }^{9,34}$ Other medications used to treat depression can also lead to serotonin syndrome when used with amphetamines. These include SNRIs, St John's wort, bupropion (Wellbutrin), and lithium. ${ }^{34}$

Early symptoms of serotonin syndrome include tachycardia, shivering, diarrhea, diaphoresis, muscle cramps, agitation, and elevated body temperature. These are followed by hypertension, hyperthermia, hyperreflexia, delirium, tremors, and rigidity. If not treated, hypertensive crisis and severe hyperthermia can result in death. ${ }^{9,34}$ Stimulants also increase blood pressure by increasing extracellular norepinephrine and dopamine. Moreover, concurrent use of stimulants with either SNRIs or bupropion (with a similar structure to amphetamine) can increase blood pressure. ${ }^{9}$

The actual incidence of serotonin syndrome from concurrent use of medications used to treat depression and stimulants is unknown. Cooper and Sejnowski ${ }^{34}$ have reviewed the agents involved and the increasing frequency of serotonin syndrome over time, as SSRIs and SNRIs have become more frequently prescribed. The 2012 "Annual report of the American Association of Poison Control Centers' National Poison Data System" identified 47,115 toxic SSRI/SNRI exposures (the majority of which involved concurrent ingestion of other agents) and 89 deaths. ${ }^{35}$ Boyer $^{36}$ states that serotonin syndrome may be underrepresented in the surveillance data because: (1) the symptoms of serotonin syndrome may be attributed to another cause, (2) mild symptoms may resolve within 24 to 74 hours or are ignored or dismissed, or (3) the clinician does not suspect or is not aware of the condition (a study in 1999 found that $85 \%$ of physicians were unaware of serotonin syndrome as a clinical diagnosis ${ }^{37}$ ). Future studies should aim to assess the prevalence of both CYP2D6 inhibition and the risk of serotonin syndrome related to stimulants and concurrently prescribed medications for treatment of depression.

Currently, prescribing information for SSRIs and SNRIs states that they inhibit hepatic CYP2D6; however, the examples of medications metabolized by CYP2D6 that should not be taken with SSRIs/SNRIs exclude amphetamines. Also, prescribing information for SSRIs and SNRIs do not mention amphetamines among the drugs ${ }^{34}$ that can precipitate serotonin syndrome, when taken concurrently with SSRIs or SNRIs. Recent continuing education programs for prescribers and pharmacists ${ }^{34,38,39}$ will help clinicians become more aware of the etiology, epidemiology, diagnosis, and treatment of serotonin syndrome. However, the US Food and Drug Administration should consider requiring statements on both prescribing information and package inserts - regarding the potential increased risk of adverse effects from concurrent use of amphetamines and prescription antidepressants - if sufficient research evidence supports such a policy.

A recent investigation of medical versus nonmedical use of prescription drugs among college students ${ }^{8}$ reported the following outcomes, respectively: (1) sleep aids: 3.3\% versus $2 \%$, (2) sedative/anxiety medication: $3.4 \%$ versus $2.9 \%$, (3) stimulants: $2.2 \%$ versus $5.4 \%$, and (4) prescription pain relievers: $24.4 \%$ versus $9.3 \%$. Past studies have also found

Table 6 Binary logistic regression statistics for predictors of user status among respondents taking prescription medication for depression, final model

\begin{tabular}{llllllll}
\hline Predictor & Coefficient & SE coefficient & $Z$ & P-value & Odds ratio & $\frac{95 \% \text { Cl }}{\text { Lower }}$ & Upper \\
\hline Constant & & & & & & & \\
No group affiliation & -2.69485 & 0.483689 & -5.57 & 0.000 & & 1.07 & 13.38 \\
Nicotine craving & 1.33104 & 0.644333 & 2.07 & 0.039 & 3.78 & 3.01 & 62.70 \\
\hline
\end{tabular}

Notes: Log-likelihood -33.733 . Test that all slopes are zero: $G=16.749, d f=2, P$-value $=0.000$.

Abbreviations: $\mathrm{Cl}$, confidence interval; $d f$, degrees of freedom; $\mathrm{SE}$, standard error. 
Table 7 Goodness-of-fit tests

\begin{tabular}{llll}
\hline Method & Chi-square & df & P-value \\
\hline Pearson & 0.0336663 & I & 0.854 \\
Deviance & 0.0331446 & $\mathrm{I}$ & 0.856 \\
Hosmer-Lemeshow & 0.0066045 & $\mathrm{I}$ & 0.935 \\
Brown: & & & \\
$\quad$ General alternative & 0.0336629 & 2 & 0.983 \\
$\quad$ Symmetric alternative & 0.0321470 & $\mathrm{I}$ & 0.858 \\
\hline Abbreviation:
\end{tabular}

that undergraduate students in the United States engaged in nonmedical use of stimulants much more frequently than their non-college-attending counterparts. ${ }^{28,40}$

Based on the findings discussed, it is clear that the college lifestyle chosen by some students - characterized by sleep deprivation, mixing alcohol and drug use at social events, using stimulants as "study aids", and the like - is a serious environmental and public health risk across the country. In a recent college study, approximately $50 \%$ of respondents who reported frequent or non-oral use of nonmedical prescription stimulants in the past month also reported depressed mood. ${ }^{41}$

The present study contributes to the literature by examining the prevalence of concurrent use of amphetamine stimulants and prescribed medication to treat depression among college students. Unlike other previous research, this study also investigated self-health rating, symptomatology, and concurrently self-medication practices (including how often and when agents were ingested) among those who used a stimulant concurrent with prescribed medication to treat depression.

Of the 1,976 valid survey responses, $4.0 \%$ of survey respondents reported using stimulants in the past month. This stimulant use percentage falls within the $2 \%-8 \%$ range of previously published surveys. ${ }^{3,4,8,41}$ The current survey was conducted several weeks before the midterm exams rather than during the midterm or final exam period when stimulant use typically increases. ${ }^{10,42}$ This scenario may also explain the wide range in reported prevalence rates among college students in previous studies. ${ }^{26}$ Although respondents were informed of the anonymous nature of the survey (and that illicit drug use was not an objective of the survey), stimulant use could have been under reported due to their fear associated with the consequences of reporting illicit drug use.

Compared with non-stimulant users, self-health was rated more poorly and negative health symptoms were reported as more significant among stimulant users. Undesirable health symptoms reported included depression, diarrhea, difficulty sleeping, fatigue, dizziness and unsteadiness, difficulty concentrating, and nicotine craving. Of respondents mentioning amphetamine-stimulant use, 33\% indicated symptoms from depression, which is more than twice greater than the $13 \%$ of respondents who reported no stimulant use. Tobacco use was also doubly as common and nicotine craving was nine times more prevalent - among stimulant users than among nonusers - whether or not they were taking a prescription medication to treat depression. The findings regarding nicotine craving are of particular interest as recent studies found depressive symptomatology in amphetamine users to be significantly associated with nicotine craving and smoking-cessation difficulty. ${ }^{43,44}$

Even though the percentage of respondents in the current study who took both stimulants and prescription medication for depression $(0.8 \%)$ is not high, the co-mingling of these two types of substances could cause CYP2D6 enzyme inhibition and potentially increased serum levels of amphetamine and serotonin with severe health consequences for these students. An important component of adherence to an antidepressant regimen is avoiding concurrent use of other medications that can cause adverse drug-drug interactions. Students taking prescription medication for depression were found to be four times more likely to use amphetamine stimulants than those not taking prescribed medication for depression. Of stimulant users with symptoms of depression, more than a third reported taking a prescription medication for treating depression. The survey respondents being treated for depression reported obtaining medication information from their primary care providers (including $47 \%$ of those who also used stimulants and $37 \%$ of those who did not use stimulants). In contrast, of the stimulant users who did not take prescription medication for treating depression, none reported consulting their primary care provider for such information.

Of the students who reported using stimulants and prescription agents to treat depression, 93\% also reported anxiety as a condition in the past year. It appears unlikely that these stimulants were both prescribed and monitored by the prescriber(s). If the stimulants were indeed legally prescribed to treat ADHD and comorbid depression in students exhibiting symptoms of apathy and hypersomnia, ${ }^{31,32}$ then anxiety (a possible side effect of stimulant use) may have resulted without prescriber monitoring. It should be noted that in this sample (biased with predominantly white females), the "predictor" variables in the binary logistic regression model are not actual predictors of whether a student taking prescribed medication for depression will use stimulants. They are variables associated with the respondent reporting stimulant use. Future longitudinal studies should collect data on symptoms along with patterns of drug and alcohol use to determine if these (or other) variables predispose students taking a prescription for depression therapy to use 
stimulants or vice versa. Based on the results of this study, it is considered prudent for clinicians monitoring students under treatment for depression to continuously inquire about their concurrent medication use (prescribed, OTC, and illicit agents), sleep patterns, participation in extracurricular groups, and symptoms of nicotine craving.

Given the potential risks and side effects of stimulant use alone or concurrently with alcohol and other medications such as antidepressants, health care providers should query students about their symptoms and self-medication practices, in addition to providing tailored education at the point of care during each visit. ${ }^{15}$ Students with symptoms of depression and/or taking antidepressants should be given explicit warnings concerning amphetamine-stimulant use. They should be counseled at all points of care about the symptoms of serotonin syndrome and potential interactions with agents with which they may self-medicate such as amphetamines as well dextromethorphan cough suppressants, St John's wort, ginseng, cocaine, ecstasy (3,4-methylenedioxy methamphetamine [MDMA]), and/or mescaline.

\section{Limitations}

The online survey adopted by the study had several limitations, even though it was efficient in reaching a large participant pool. First, respondents could not ask for clarification of the survey content, which may have resulted in incorrect answers, incomplete surveys, or aborted submissions. Second, the length of time required for completing the survey could vary among respondents. For instance, when the respondents answered "yes" to a self-medication question in the survey, they were prompted with an additional question and so on. Hence, respondents could answer "no" to selected questions or skip entering medication-use information in the text-space provided - to avoid further prompts. Third, the university considers students a "vulnerable population", therefore the institutional review board did not permit the investigation of: (1) whether stimulants were used for medical or nonmedical purposes, (2) how medications were acquired, or (3) whether individual students were diagnosed with ADHD (which is usually treated with stimulants). Fourth, the small number of males in the sample might have reduced the range of male responses and resulted in a bias.

That only $2.9 \%$ of respondents reported using an energy drink in the past month was unexpected. This stands in contrast to the results of Woolsey et al's 2009 online survey ${ }^{29}$ that found $83 \%$ of the 267 respondents reported using energy drinks in the past year and $15 \%$ indicated using energy drinks only when drinking alcohol. There may be two reasons why the results from Woolsey et al's ${ }^{29}$ study are different from those of the current study. First, energy drink users may have been over represented in the Woolsey et $\mathrm{al}^{29}$ study, which focused on surveying energy drink use and had a very low response rate. Second, the low reporting rate of energy drink use in the current study might have in part resulted from the recent state ban on energy drinks (and associated public relations campaign), which could have led to a temporary drop in such use during the survey period.

\section{Conclusion}

As far as the authors are aware, this study is the first to have assessed self-health rating, symptomatology, and polypharmacy among college students' concurrent use of amphetamine stimulants and medications prescribed for treatment of depression. Further investigation of knowledge and self-medication practices of college students is needed to increase our understanding of how best to educate and counsel students.

Based on the results of this study, colleges and universities should develop, implement, and evaluate preventative and intervention programs - aimed at reducing student misconceptions about the dangers of stimulant use - and the risks of concurrent use of stimulants with alcohol, tobacco, antidepressants, and/or other drugs. This education content could be easily added to any existing substance-abuse prevention programs. These programs should also be aimed at establishing a correct social norm regarding prescription stimulant use; this correct norm would dictate that prescription stimulants are and should be intended for medical use only.

Continuing education programs for health providers of college students (both in the community and at student health services) could target improving provider knowledge of potential adverse interactions of stimulants with alcohol, tobacco, and other drugs (antidepressants in particular). Additional training for providers and preprofessional students should improve their skills in assessing student selfmedication practices - as well as identifying and counseling students with symptoms of depression - associated with the use of stimulants. These efforts will promote and increase safe self-medication literacy and practices among college students to improve their medication adherence, physical health, and psychological well-being.

\section{Acknowledgments}

Undergraduate nursing honors students, who participated in designing the research study, testing the survey software, and 
analyzing survey responses, included Kara Dazkevich (BS, RN), Heather Buck (BS, RN), Michelle Santos (BS, RN), and Kristen Summers (BS, RN). Without their intellectual curiosity, diligence, and enthusiastic teamwork, this study could not have been successfully conducted. The authors are grateful to Anne Marie Biernacki, Chief Technology Officer, ActualMeds Corp for facilitating the survey deployment and hosting the survey on the ActualMeds secure server.

This work was supported by the University of Connecticut through a faculty small grant (to PJN); the University of Connecticut Honors Program (to KV). ActualMeds Corp supported the survey deployment and hosting on the ActualMeds secure server as well as publication costs.

\section{Disclosure}

The University of Connecticut granted an exclusive license for the survey software used in this study to the ActualMeds Corp. in 2009. Patricia J Neafsey and Carolyn Lin receive a percentage of the software license fee charged by the University of Connecticut. Patricia J Neafsey is a co-founder and Principal Scientist at ActualMeds Corp. The University of Connecticut and Patricia J Neafsey are shareholders of ActualMeds Corp. Kim Vo does not have any financial competing interests.

\section{References}

1. Title 21 Code of Federal Regulations [updated September 9, 2014]. Available from http://www.deadiversion.usdoj.gov/schedules/orangebook/c_ cs_alpha.pdf. Accessed October 10, 2014.

2. Controlled substances [updated September 9, 2014]. US department of Justice; Drug Enforcement Administration; Office of Diversion Control. Available from http://www.deadiversion.usdoj.gov/21cfr/ cfr/1306/1306_12.htm. Accessed October 10, 2014.

3. McCabe SE, Knight JR, Teter CJ, Wechsler H. Non-medical use of prescription stimulants among US college students: prevalence and correlates from a national survey. Addiction. 2005;100(1):96-106. Erratum in Addiction. 2005;100(4):573.

4. Weyandt LL, Janusis G, Wilson KG, et al. Nonmedical prescription stimulant use among a sample of college students: relationship with psychological variables. J Atten Disord. 2009;13(3):284-296.

5. McCabe SE, Schulenberg JE, Johnston LD, O’Malley PM, Bachman JG, Kloska DD. Selection and socialization effects of fraternities and sororities on US college student substance use: a multi-cohort national longitudinal study. Addiction. 2005;100(4):512-524.

6. White BP, Becker-Blease K, Grace-Bishop K. Stimulant medication use, misuse, and abuse in an undergraduate and graduate student sample. $\mathrm{J} \mathrm{Am}$ Coll Health. 2006;54(5):261-268.

7. Teter CJ, McCabe SE, Boyd CJ, Guthrie SK. Illicit methylphenidate use in an undergraduate student sample: prevalence and risk factors. Pharmacother. 2003;23(5):609-617.

8. McCabe SE, West BT, Teter CJ, Boyd CJ. Trends in medical use, diversion, and nonmedical use of prescription medications among college students from 2003 to 2013: Connecting the dots. Addict Behav. 2014;(39):1176-1182.

9. Drug Interactions. Drug Facts and Comparisons. Facts \& Comparisons [database online]. St. Louis, MO: Wolters Kluwer Health, Inc; 2013. Accessed December 13, 2013.
10. DeSantis AD, Webb EM, Noar SM. Illicit use of prescription ADHD medications on a college campus: a multimethodological approach. J Am Coll Health. 2008;(57):315-324.

11. DeSantis AD, Noar SM, Webb E. Speeding through the frat house: a qualitative exploration of nonmedical ADHD stimulant use in fraternities. J Drug Educ. 2010;40(2):157-171.

12. DeSantis AD, Hane AC. "Adderall is definitely not a drug": justifications for the illegal use of ADHD stimulants. Subst Use Misuse. 2010; 45(1-2):31-46.

13. McCabe SE, Teter CJ, Boyd CJ. Medical use, illicit use, and diversion of abusable prescription drugs. J Am Coll Health. 2006;54(5):269-276.

14. ActualMeds Smartlist ${ }^{\mathrm{TM}}$ [database online]. East Hartford, CT: ActualMeds Corporation; 2013. Accessed October 1, 2011.

15. Neafsey PJ, M'lan CE, Ge M et al. Reducing Adverse Self-Medication Behaviors in Older Adults with Hypertension: Results of an e-health Clinical Efficacy Trial. Ageing Int. 2011;36(2):159-191.

16. SAS Institute Inc. SAS/STAT ${ }^{\circledR}$ 9.2. User's Guide. Cary, NC: SAS Institute, Inc.

17. University of Connecticut. Uconn.edu/students [updated 2012]. Storrs, CT: University of Connecticut. Available from: http://www.oir.uconn. edu/StorrsTrend_Fall_2012.pdf. Storrs, CT: University of Connecticut; nd_[updated 2012]._Accessed December 6, 2012.

18. Carroll BC, McLaughlin TJ, Blake DR. Patterns and knowledge of nonmedical use of stimulants among college students. Arch Pediatr Adolesc Med. 2006;160(5):481-485.

19. Teter CJ, McCabe SE, Cranford JA, Boyd CJ, Guthrie SK. Prevalence and motives for illicit use of prescription stimulants in an undergraduate student sample. J Am Coll Health. 2005;53(6):253-262.

20. Rabiner DL, Anastopoulos AD, Costello EJ, Hoyle RH, McCabe SE, Swartzwelder HS. Motives and perceived consequences of nonmedical ADHD medication use by college students: are students treating themselves for attention problems? J Atten Disord. 2009;13(3): 259-270.

21. DeSantis AD, Noar SM, Webb E. Nonmedical ADHD stimulant use in fraternities. J Stud Alcohol Drugs. 2009;70(6):952-954.

22. Kroutil LA, Van Brunt DL, Herman-Stahl MA, Heller DC, Bray RM, Penne MA. Nonmedical use of prescription stimulants in the United States. Drug Alcohol Depend. 2006;(84):135-143.

23. Pilkinton M, Cannatella A. Nonmedical Use of prescription stimulants: age, race, gender, and educational attainment patterns. J Hum Behav Soc Environ. 2012;22(4):409-420.

24. Weyandt LL, Marraccini ME, Gudmundsdottir BG, et al. Misuse of prescription stimulants among college students: a review of the literature and implications for morphological and cognitive effects on brain functioning. Exp Clin Psychopharmacol. 2013;21(5): 385-407.

25. Substance Abuse and Mental Health Services Administration, Office of Applied Studies. The NSDUH Report: Nonmedical Use of Adderall ${ }^{\circledR}$ among Full-Time College Students. Rockville, MD: Substance Abuse and Mental Health Services Administration, Office of Applied Studies; April 9, 2009. Available from: http://www.samhsa.gov/data/2k9/ adderall/adderall.pdf. Accessed December 6, 2012.

26. Bavarian N, Flay BR, Smit E. An exploratory multilevel analysis of nonprescription stimulant use in a sample of college students. J Drug Issues. 2014;44(2):132-149.

27. Kang J, Czart Ciecierski C, Malin EL, et al. A latent class analysis of cancer risk behaviors among U.S. college students. Prev Med. 2014;64:121-125.

28. Johnston LD, O’Malley PM, Bachman JG, Schulenberg JE. Monitoring the Future National Survey Results on Drug Use, 1975-2005. Vol 2, College students and adults ages, 19-45. NIH publication 07-6206. Bethesda, MD: National Institute on Drug Abuse; 2006. Available from: http://www.monitoringthefuture.org/pubs/monographs/vol2_2005. pdf. Accessed December 6, 2012.

29. Woolsey CL, Barnes LB, Jacobson BH, et al. Frequency of energy drink use predicts illicit prescription stimulant use. Substance Abuse 2014;35(1):96-103. 
30. Allen KJ, Gabbay FH. The amphetamine response moderates the relationship between negative emotionality and alcohol use. Alcohol Clin Exp Res. 2013;37(2):348-360.

31. Findling RL. Open-label treatment of comorbid depression and attentional disorders with co-administration of serotonin reuptake inhibitors and psychostimulants in children, adolescents, and adults: a case series. J Child Adolesc Psychopharmacol. 1996;6(3):165-175.

32. Gammon GD, Brown TE. Fluoxetine and methylphenidate in combination for treatment of attention deficit disorder and comorbid depressive disorder. J Child Adolesc Psychopharmacol. 1993;3(1):1-10.

33. Neafsey P, Ginsberg G, Hattis D, Sonawane B. Genetic polymorphism in cytochrome P450 2D6 (CYP2D6): Population distribution of CYP2D6 activity. J Toxicol Environ Health B Crit Rev. 2009;12(5-6): 334-361.

34. Cooper BE, Sejnowski CA. Serotonin syndrome: recognition and treatment. AACN Adv Crit Care. 2013;24(1):15-20.

35. Mowry JB, Spyker DA, Cantilena LR Jr, Bailey JE, Ford M. 2012 Annual Report of the American Association of Poison Control Centers' National Poison Data System (NPDS): 30th Annual Report. Clin Toxicol (Phila). 2013;51(10):949-1229.

36. Boyer EW. Serotonin syndrome. Up To Date [serial online]. 2014, July 2 [updated November 17, 2014]. Available from: http://www.uptodate. com/contents/serotonin-syndrome. Accessed November 26, 2014.

37. Mackay FJ, Dunn NR, Mann RD. Antidepressants and the serotonin syndrome in general practice. Br J Gen Pract. 1999;49(448):871-874.
38. Brown CH. Drug-induced serotonin syndrome. US Pharmacist. 2010;35(11):HS-16-HS-21.

39. Cushing TA, Kim H, Benzer TI. Selective serotonin reuptake inhibitor toxicity. Medscape [serial online]. 2014, February 26. Available from: http://emedicine.medscape.com/article/821737-overview. Accessed November 26, 2014.

40. Herman-Stahl MA, Krebs CP, Kroutil LA, Heller DC. Risk and protective factors for methamphetamine use and nonmedical use of prescription stimulants among young adults aged 18 to 25. Addict Behav. 2007;32(5):1003-1015.

41. Teter CJ, Falone AE, Cranford JA, Boyd CJ, McCabe SE. Nonmedical use of prescription stimulants and depressed mood among college students: frequency and routes of administration. J Subst Abuse Treat. 2010;38(3):292-298.

42. Hanson CL, Burton SH, Giraud-Carrier C, West JH, Barnes MD, Hansen B. Tweaking and tweeting: exploring Twitter for nonmedical use of a psychostimulant drug (Adderall) among college students. J Med Internet Res. 2013;15(4):e62.

43. Sonne SC, Nunes EV, Jiang H, Tyson C, Rotrosen J, Reid MS. The relationship between depression and smoking cessation outcomes in treatment-seeking substance abusers. Am J Addict. 2010;19(2): 111-118.

44. Garfield JB, Lubman DI, Yücel M. Anhedonia in substance use disorders: a systematic review of its nature, course and clinical correlates. Aust N Z J Psychiatry. 2014;48(1):36-51.
Patient Preference and Adherence

\section{Publish your work in this journal}

Patient Preference and Adherence is an international, peer-reviewed, open access journal that focuses on the growing importance of patient preference and adherence throughout the therapeutic continuum. Patient satisfaction, acceptability, quality of life, compliance, persistence and their role in developing new therapeutic modalities and compounds to optimize

\section{Dovepress}

clinical outcomes for existing disease states are major areas of interest for the journal. This journal has been accepted for indexing on PubMed Central The manuscript management system is completely online and includes a very quick and fair peer-review system, which is all easy to use. Visit http://www. dovepress.com/testimonials.php to read real quotes from published authors. 